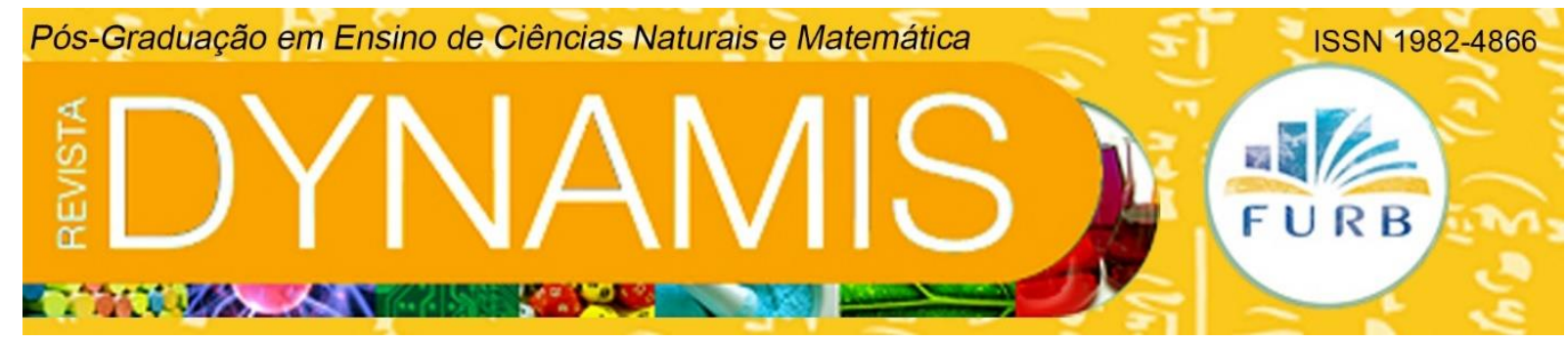

\title{
TECNOLOGIAS DA INFORMAÇÃO E COMUNICAÇÃO NO ENSINO E APRENDIZAGEM DE CIÊNCIAS
} Information and communication technology in the process of teaching
and learning in Sciences

Maristela Gonçalves Giassi

Doutora em Educação Científica e Tecnológica

Docente do Curso de Ciências Biológicas da Universidade

Universidade do Extremo Sul Catarinense - UNESC

mgi@unesc.net

Mariana Colombo Ramos

Graduada em Ciências Biológicas

Universidade Federal do Rio Grande do Norte - UFRN

marianacolombo_07@hotmail.com 


\title{
Resumo
}

O mundo caminha cada vez mais em direção a inovações tecnológicas, sendo que a Tecnologia da Informação e Comunicação - TIC, tem se modificado e avançado sempre mais. Assim, este estudo teve como objetivo investigar a eficácia do uso de TICs no processo de ensino e aprendizagem de Ciências. Usou-se uma pesquisa qualitativa e descritiva, com duas turmas de sexto ano do Ensino Fundamental em uma escola da rede Pública Estadual de Criciúma/Santa Catarina. Uma turma foi o lócus da experiência e a outra, controle. Os alunos fizeram trabalhos utilizando pesquisa na internet, programa power point, criação de vídeo no programa movie maker, câmera e gravador de áudio do celular e vídeos do youtube. Os estudantes fizeram excelentes trabalhos resultando em grande aprendizado de todos.

Palavras-chave: Educação. Ensino de Ciências. Tecnologias da Informação e Comunicação.

\begin{abstract}
The world is moving increasingly towards technological innovations and the Information and Communication Technology - ICT has been changing and progressing more and more. Therefore, this article aims to investigate the efficacy of using ICTs in the process of teaching and learning Science. A qualitative and explanatory research was applied in a public school in Criciúma/Santa Catarina. Two $6^{\text {th }}$-year-class of Elementary School were used, one as subject and another as control. The students made de use of the internet, Microsoft Power Point, videos with Microsoft Movie Maker, cellphone cameras and audio recorder and Youtube videos. The students did an excellent job with great learning for all of them.
\end{abstract}

Keywords: Education. ICT - Information and Communication Technologies. Science Teaching.

\section{INTRODUÇÃO}


Vivemos em uma sociedade que recebe uma enorme quantidade de produtos tecnológicos resultantes dos avanços científicos alcançados pela humanidade. No entanto, estes avanços nem sempre chegam a todas as pessoas, consequência de diferenças socioeconômicas e políticas, entre outros, que permeiam esse mundo globalizado. Essa diferença está presente também na maioria das escolas de nosso país, que mesmo contando com um corpo de profissionais capacitado, muitas vezes esbarram nas condições de infraestrutura das escolas, especialmente no que tange a recursos tecnológicos, para atuarem de maneira mais dinâmica.

Diante desses avanços, não só tecnológicos e científicos, mas também culturais, sociais e econômicos, é natural o surgimento de novos paradigmas, inclusive no campo da educação, que tende a incluir as Tecnologias da Informação (TICs), já que não podemos prescindir de seu uso. Esse conjunto de tecnologias, de acordo com Belloni (2005), são o resultado da fusão de três grandes vertentes: a informática, as telecomunicações e as mídias eletrônicas. E Ramos (2012, p. 6) complementa direcionando as TICs para as salas de aula, caracterizando-as como tecnologias educacionais, que podem ser entendidas como um "conjunto de técnicas, processos e métodos que utilizam meios digitais e demais recursos como ferramentas de apoio aplicadas ao ensino, com a possibilidade de atuar de forma metódica entre quem ensina e quem aprende".

Tanto para Ramos (2012), como para Giassi e Tramontin (2015) falar em tecnologias na sala de aula, não quer dizer falar somente sobre aqueles recursos utilizados por alguns professores para ministrar suas aulas, como quadros digitais, computadores, data show, vídeos, entre outros, esses estão legitimados. Seu uso vai depender dos próprios professores e de sua presença nas escolas, o que para muitas delas, ainda é um aparato difícil de ser alcançado. Mas falamos também daqueles recursos que os próprios estudantes têm à mão, como o celular, o tablete, justamente porque são eles o alvo de debates e controvérsias nas salas de aulas. Muitos professores e equipes pedagógicas afirmam que seu uso provoca distrações e conversas paralelas, atrapalham as aulas e favorecem as famosas "colas", entre outras coisas, apontando ainda a legislação que proíbe o seu uso em sala de aula (GIASSI; TRAMONTIN, 2015). Entretanto, o que se pretende é aproveitar também estes recursos que os estudantes trazem para a aula para transformá-los em aliados nos processos de ensino e aprendizagem.

Nesse sentido essa pesquisa procurou utilizar alguns tipos de TIC, com o propósito de incluir as diversas possibilidades de seu uso em sala de aula. Tanto aquelas tecnologias já de domínio dos professores, de grande interesse didático pedagógico, como aquelas usadas pelos alunos no seu dia a dia.

O processo evolutivo ocorrido com as TICs ao longo da história possibilita equipar uma escola com o que há de ponta nesse sentido, contudo, as primeiras tecnologias que nelas entraram, permanecem até hoje como principal suporte utilizado pelo professor para trabalhar em suas aulas: o livro e o quadro de giz. A rapidez da invasão das tecnologias na vida das pessoas e dos espaços escolares intimida muitos professores, pois sentem-se despreparados frente ao desafio de incorporá-las ao cotidiano escolar.

Para Libâneo (2011) esses avanços interferem essencialmente no contexto das escolas e na prática docente, até porque, de acordo com o autor, o objetivo maior das escolas é a aprendizagem dos alunos, e isso implica em proporcionar a melhor qualidade possível dessa aprendizagem. É nela que os estudantes se preparam para compreenderem o mundo e nele atuarem. Dentro das escolas as TIC estão presentes nas Secretarias para as funções burocráticas, em laboratórios de informáticas para uso de estudantes e professores e, principalmente, nas mãos de seus estudantes, que não dispensam o celular, por exemplo, para muitas atividades do seu dia a dia. 
No entanto este tema ainda é espaço de grandes controvérsias nas escolas. Não existe um consenso entre os educadores, gestores e estudantes (MARTINHO; POMBO, 2009, GIASSI; TRAMONTIN, 2016). Segundo Martinho e Pombo (2009) as TICs precisam ser incorporadas ao processo de ensino - aprendizagem, pois, para eles, são ferramentas que podem contribuir para valorizar as práticas pedagógicas já que possibilitam o acesso a informação com maior flexibilidade e também diversidade de suporte no seu tratamento e apresentação. Nessa interação de tecnologias para os mais diversos usos, surge a necessidade dos professores conhecê-las e orientarem seus alunos sobre as possibilidades e as armadilhas desses recursos.

As Orientações Curriculares Nacionais (BRASIL, 2008) chamam a atenção para o impacto que as tecnologias provocam na sociedade. Esta cobra dos indivíduos uma capacitação para poder usá-las, por isso mesmo, para os referidos documentos é necessário antes de tudo entendê-la como parte deste processo, chamando atenção para as armadilhas da economia e para as demandas do mercado. Por isso evoca a atenção das escolas, para que seu uso sirva antes e acima de tudo como uma ferramenta, um recurso no processo ensino aprendizagem, onde professor e aluno possam interagir e aprender a partir de suas potencialidades.

Do mesmo modo, Soffner (2013) complementa que a introdução das TICs nas escolas pode servir também para melhorar a qualidade das aulas, pois desperta a motivação dos estudantes que se identificam com as tecnologias e contribui no desenvolvimento de competências para a vida.

\footnotetext{
Deste ponto de vista tais tecnologias de apoio ao desenvolvimento cognitivo poderão ser consideradas tecnologias da aprendizagem. Esta aprendizagem leva ao desenvolvimento de competências para a vida, que pode ser considerada uma contínua interação entre o indivíduo e seu meio. O conhecimento e a aprendizagem são as formas pelas quais nos adaptamos às mudanças desse meio, e as novas tecnologias de informação e comunicação têm seu papel nestas questões epistemológicas. (SOFFNER, 2013, p. 155)
}

Para o autor, o professor precisará então incorporar outro papel, deverá passar de expositor dos conteúdos para o aluno, para um papel de mediador desses conteúdos, desafiando e motivando o estudante para o aprendizado. $\mathrm{O}$ autor entende que isso contribuirá até para o combate a indisciplina e ao pouco sucesso percebido nas escolas de hoje.

Freire, Papert (1995) e Soffner (2013) afiançam que as TICs podem servir de estímulo no processo de aprendizagem aos estudantes. Destacam que cabe ao professor promover esta aprendizagem por meio de atividades que os desafiem e os motivem para a exploração, a reflexão e a descoberta de conceitos relacionados com os problemas que desenvolve nos seus conteúdos, e, para isso, indicam as TICs nos ambientes escolares. Para os autores, também o aluno é atingido pelas tecnologias. Estes sofrem alterações no seu modo de comunicar-se, de pesquisar e até mesmo de se relacionar, o que se reflete no seu sentido crítico, sua forma de análise e mesmo na sua autonomia. Os autores entendem que as TICs poderão auxiliar os estudantes a construir seu conhecimento, a entender e melhor solucionar situações de sua vida, já que consomem e também produzem informações via TIC. Por isso mesmo, o professor precisa ficar atento a tudo isso, porque a informação nestes casos, nem sempre é sinônimo de conhecimento.

Freire e Papert (1995) destacam que neste momento da história humana a educação pode beneficiar-se com o uso das TICs, pois estas se apresentam como um novo modelo pedagógico, proporcionando a conversão de informações em conhecimento. Embora os autores valorizem sobremaneira a ação humana, esta forma de inserir os conhecimentos proporciona também uma 
nova forma de olhar a pesquisa e a construção desses conhecimentos. Além disso, para eles, as tecnologias podem contribuir para a inclusão digital de alunos e professores, especialmente aqueles, que inseridos nesta sociedade, ainda não possuem acesso a esses recursos.

Para Freire (2011) a curiosidade que nos impulsiona para o conhecimento, para a descoberta, nos oferece munição para aprender e para ensinar, porque quando descobrimos o novo, ficamos motivados a comunica-lo. Nesta troca se confirma a proposta de Freire (2005), de que a escola não tem que ser apenas um local para transferência de conteúdos, mas sim de ensino e aprendizagem e essa poderá se dar de todas as formas e, nesse viés, por meio das TICs.

Neste cenário, segundo Serafim e Souza (2008, p. 20),

\begin{abstract}
A escola de hoje é fruto da era industrial, foi estruturada para preparar as pessoas para viver e trabalhar na sociedade que agora está sendo convocada a aprender, devido às novas exigências de formação de indivíduos, profissionais e cidadãos muito diferentes daqueles que eram necessários na era industrial.
\end{abstract}

Para os autores, o mundo caminha cada vez mais em direção a inovações tecnológicas, sendo que a Tecnologia da Informação e Comunicação - TIC, tem se modificado e avançado e assim, era esperado que houvesse mudanças significativas na educação, sendo que cada vez mais vem fazendo parte da vida do aluno. No entanto, há uma dificuldade de explorar devidamente todas as suas possibilidades, especialmente nas escolas públicas, cuja máquina depende de vários intervenientes para funcionar adequadamente. No entanto, sabe-se que o seu uso permite aproximar o aluno das atividades, das pesquisas, dos conteúdos trabalhados em sala de aula, bem como, possibilita maior interação entre eles.

Devido à sua versatilidade, segundo Martinho e Pombo (2009), Murphy (2003), as TICs, apresentam diversas vantagens para serem utilizadas nas escolas, podem ser utilizadas como instrumento de elaboração de gráficos e tabelas; acesso à bases de dados; como fontes de referências; como meio de comunicação por meio do correio eletrônico; para discussões on line; apresentações, entre tantos outros, que se constitui como uma ferramenta para o ensino de Ciências nas escolas.

Perrenoud (2000) complementa que as TICs transformam não só a maneira de se comunicar, mas também, de estudar, trabalhar, decidir e de pensar e que as escolas não podem ignorar isso. Santos (2007) acrescenta entre os benefícios do uso das TICs, o fato de tornar o ensino das ciências mais interessante; propicia mais observação, discussão e análise e ainda maior possibilidade de criar situações de comunicação e colaboração. Para os autores as mídias apresentam grande poder pedagógico, já que se utilizam da imagem e essas são essenciais, especialmente nas aulas de ciências cuja abstração nem sempre é bem captada por todos. Nesse sentido o uso de TICs potencializa sobremaneira o processo de aprendizagem.

Segundo Kaieski, Grings e Fetter (2015), as tecnologias móveis como, por exemplo, whatsapp estão chegando e podem agregar dentro da sala de aulas. Os autores observam que as escolas deveriam aproveitar melhor este recurso inserindo programas de ensino que possam utiliza-los já que os jovens gostam, possui baixo custo e traz eficiência para o ensino. Os jovens são os que mais rápido aderem às novas tecnologias e estão sempre em busca de algo novo. Muitas vezes, estes já vêm para a escola com um conhecimento sobre tecnologias maior que a dos professores. Giassi e Tramontim (2016) identificaram certo temor na utilização das TICs por alguns professores e a justificativa era justamente a expertise dos estudantes em detrimento da sua. Nesse sentido, o professor não pode ter medo de incluir as TIC como uma ferramenta do conhecimento, segundo Moura e Brandão (2013, p. 2) 
O uso das TIC no ambiente escolar precisa ser visto pelos professores, não como uma ameaça a sua forma de ensinar, mas como um aliado para a promoção do aprendizado, porém não esquecendo que o professor é quem determina o conteúdo e o aluno é o sujeito que manifesta o melhor caminho para poder assimilá- lo.

Para os autores a utilização de novas tecnologias requer do professor também novas competências para isso. Exige outras formas de se relacionar com o conhecimento. Para utilizar as TICs o professor necessita propor situações significativas tanto para ele como para o aluno, já que haverá ali troca de experiências e envolvimento de busca do conhecimento. O emprego de tecnologia no dia-a-dia das escolas pode representar a oportunidade de mudança do foco da aula centrada no professor, agora para o aluno que passa a assumir o processo de seu aprendizado, de sua educação.

Este cenário motivou esta pesquisa que teve como objetivo investigar a eficácia do uso de tecnologias no processo de ensino e aprendizagem de Ciências.

\section{PROCEDIMENTOS METODOLÓGICOS}

Trata-se de uma pesquisa qualitativa em relação ao tratamento dos dados, quanto ao objetivo classifica-se como descritiva e de acordo com o procedimento, denomina-se um estudo de campo.

A pesquisa foi desenvolvida em uma escola da rede pública estadual de Criciúma Santa Catarina, com duas turmas de sextos anos do Ensino Fundamental, sendo que, em uma delas foi desenvolvida a aula com o uso de TICs e a outra, serviu como controle, nesta, foram observadas as aulas conforme a metodologia costumeira da professora. As turmas foram definidas em função do horário que melhor fechava para a bolsista e a pesquisa só teve início, depois de realizados os devidos contatos com a direção e a professora da escola.

O tema definido pela professora para desenvolver a atividade foi o Solo. Procurou-se manter o ritmo regular das aulas, obedecendo à sequência do conteúdo, justamente para se perceber o desenvolvimento de atividades com o uso de TICs no cotidiano de uma escola existente no sistema público de ensino. As atividades foram planejadas pela bolsista pesquisadora e pela professora orientadora, juntamente com a professora da turma. Posteriormente a bolsista e a professora atuaram juntas na turma onde a atividade foi realizada.

No primeiro momento do desenvolvimento da pesquisa, a bolsista verificou se os alunos sabiam lidar com o computador, pesquisar na internet, fazer um power point, quais possuíam celular, para assim, dividir a turma em grupos para realização das atividades. Foi feito um sorteio para ver qual tecnologia e que parte do conteúdo definido pelo professor, cada grupo iria utilizar para a atividade, constituindo-se então, cinco (5) grupos:

a) para o tema "Erosão e Desmatamentos", foi designado a Câmera de celular, que usaram para bater fotos de desenhos feitos por eles sobre a etapa do desmatamento e pesquisas na internet que, posteriormente, utilizaram para montar uma sequência no programa movie maker;

b) com o tema a "utilização do solo", os alunos pesquisaram na internet e montaram uma apresentação de power point; 
c) no tema "O lixo e o solo" os alunos entrevistaram as serventes da escola, tratando sobre a importância de se jogar o lixo no lugar certo e como ele prejudica o solo. Nesta atividade foi montado um vídeo no programa movie maker;

d) com o tema "O que é o solo e Tipos de Solo" os alunos pesquisaram fotos e textos na internet e montaram um power point para apresentação;

e) para o tema "recursos naturais não renováveis do solo" foi utilizado o youtube, os alunos escolheram vídeos sobre petróleo e carvão mineral.

No primeiro momento todos os grupos foram levados para sala de informática, para uma primeira busca pelo seu conteúdo e também para darem asas à sua imaginação. No segundo momento foi levado um grupo por vez, e a bolsista levou o próprio notebook, pois os computadores da escola não possuíam o programa movie maker. No terceiro momento os alunos fizeram a apresentação dos trabalhos para todo grupo, sendo que esta atividade foi avaliada.

$\mathrm{Na}$ outra turma, as aulas foram apenas de observação, sem envolvimento da bolsista. Esta participação serviu para acompanhar e comparar o envolvimento dos estudantes, a forma de condução dos mesmos conteúdos sobre solo pela professora e os resultados dos processos de ensino e aprendizagem ocorridos com as duas turmas.

\section{RESULTADOS E DISCUSSÕES}

Os resultados confirmaram que as tecnologias contribuíram para que as aulas com a turma da aplicação da atividade fossem muito bem aproveitadas por todos. Pressupomos que este bom aproveitamento deva-se ao fato de que as TIC já estejam inseridas na vida dos alunos e constituem-se em artefatos bastante apreciados por eles. Outro fator percebido e que também pode ter contribuído, imputamos à novidade na rotina da sala de aula, envolvendo outros recursos como o uso da internet e do celular.

Durante a observação na turma controle, a professora usou para dar suas aulas, apenas o livro didático e o quadro. Os alunos apenas ouviam e respondiam, meio desconfiados, a algumas questões que a professora realizava no decorrer das aulas, no sentido de promover a participação dos mesmos. Já na turma da atividade, o conteúdo foi trabalhado com as TICs, trazendo um diferencial que mostrou-se motivador dos alunos, haja vista o seu empenho em realizar a atividade que coube à cada equipe.

Durante a montagem dos trabalhos os alunos participaram ativamente, pesquisando na internet textos, imagens, vídeos. Um dos grupos fotografou com o celular, outro gravou entrevistas, também com o celular, que foram feitas com funcionários da escola. A edição do material por eles resultou em recursos criativos, sendo que o resultado final surpreendeu sobremaneira a professora regente.

O primeiro grupo que trabalhou sobre erosão e desmatamento pesquisou fotos na internet e textos para poder entender o seu tema e fizeram três desenhos para demonstrar a sequência do desmatamento. Com a pesquisa, as fotos e os desenhos, os alunos montaram um vídeo, no programa movie maker, que foi apresentado em sala de aula e do qual todos os 
integrantes do grupo participaram. Nesta ação foi necessário um auxílio inicial da bolsista para iniciarem o uso do referido programa (movie maker).

Dois grupos trabalharam com a criação de slides no programa power point. Eles também fizeram a pesquisa na sala de informática, porém como a escola trabalha com sistema Linux e não havia o referido programa, a bolsista precisou levar novamente o seu notebook para ajudar na montagem dos slides. Os alunos fizeram toda a pesquisa e a bolsista apenas ajudou na organização. Pode-se perceber que todos sabiam fazer a pesquisa no google, e se mostraram interessados, curiosos, lendo textos sobre os temas e buscando fotos. $\mathrm{O}$ grupo que trabalhou os tipos de solo trouxe para a sala fotos impressas para demonstrar melhor o que estavam falando, essa iniciativa surpreendeu a todos, principalmente a professora. Outro aspecto que chamou a atenção foi o fato de que todos os participantes dos grupos apresentaram o trabalho, que eles próprios dividiram entre si sem reclamações ou discussões e apresentaram primorosamente.

Um dos grupos teve que pesquisar vídeo no youtube, os alunos já conheciam e sabiam procurar, a única dificuldade encontrada foi com os computadores da escola, pois não estavam carregando direito os vídeos, assim os alunos escolheram e mandaram os nomes para a bolsista, que baixou os vídeos em casa e levou-os na aula seguinte. Os mesmos escolheram dois vídeos, um sobre o petróleo e o outro sobre o carvão mineral, pois o tema da equipe era "recursos não renováveis do solo", os vídeos foram exibidos para a turma.

A equipe que trabalhou o tema "o lixo e o solo" fez entrevistas, gravando áudio com três serventes da escola, e foi montado um vídeo no programa movie maker com fotos sobre o lixo e o áudio das entrevistas ao fundo. O vídeo também foi apresentado para a turma. A entrevista ajudou os alunos a conhecer melhor o trabalho dos serventes e a perceber o quanto esse trabalho é importante para a escola, destacando que se todos fizessem sua parte jogando o lixo na lixeira, contribuindo para manter a escola sempre limpa.

\section{Figura 1 -Imagens das apresentações dos grupos}
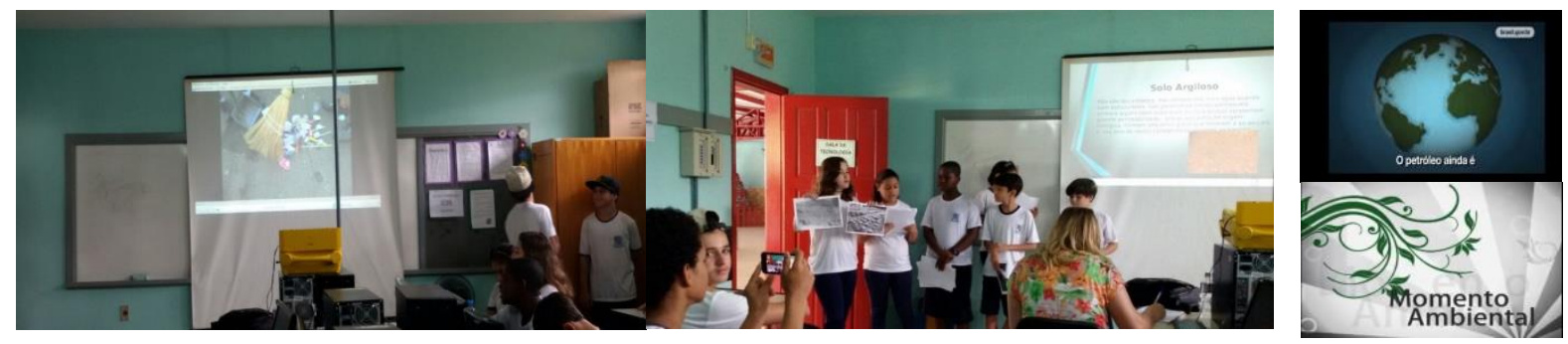

Fonte: Arquivo das autoras

Interpretou-se que os trabalhos utilizando TIC contribuíram para uma maior interação entre os estudantes e, principalmente, como pôde ser percebido durante as apresentações, para um maior aprendizado, pois os alunos aprendem com mais entusiasmo e dinamismo. Tal fato corrobora a afirmação de Moran, Masetto e Behrens (2000, p. 5) de que:

A criança aprende a informar-se, a conhecer os outros, o mundo e a si mesma. A relação com a mídia eletrônica é prazerosa e sedutora, mesmo durante o período escolar, a mídia mostra o mundo de outra forma, mais fácil, agradável. A mídia continua educando como contraposto à educação convencional, educa enquanto entretém. 
Pode-se perceber também a alegria dos alunos em utilizar os computadores e o celular em sala de aula, desenvolvendo principalmente a criatividade, sendo que eles puderam criar slides e vídeos, como também a curiosidade, iniciativa e autonomia do aluno em fazer escolhas, pois estiveram envolvidos em todo o processo da pesquisa e montagem do trabalho, aspectos destacados por Murphy (2003), Martinho e Pombo (2009), Santos (2007), Freire, (2011), entre outros estudiosos.

Com as apresentações pode-se constatar ainda quais os alunos tinham maior facilidade em comunicar-se com os colegas, quais eram mais tímidos, quais os que mais estudaram e quais não se prepararam tão bem. A professora de ciências ficou impressionada com a criatividade dos alunos o que também acabou surpreendendo a bolsista, por ser uma turma de $6^{\circ}$ ano.

Pode-se inferir com a pesquisa que o uso de TIC influência de forma positiva no aprendizado dos alunos, pois segundo autores como Kaieski, Grings e Fetter (2015), Moura e Brandão (2013), as TICs influenciam o aprendizado desde que utilizada com um objetivo e de forma consciente e que os professores não podem ter medo de utiliza-las em sala de aula, pois estas podem ser uma grande aliada do professor.

Os estudantes gostaram também de utilizar algo que já conheciam e de ficarem mais próximos da professora, do conteúdo trabalhado e entre eles mesmos, sentindo-se mais seguros, autores e empoderados do espaço sala de aula. O que para Freire (2005) é dar oportunidade para que cada um se construa como cidadão, como sujeito do seu conhecimento e não como objeto que se deixa manipular, que se deixa encher como em um depósito. Freire, (2005, p 67) observa que "só existe saber na invenção, na reinvenção, na busca inquieta, impaciente, permanente, que os homens fazem no mundo, com o mundo e com os outros. Busca esperançosa também".

Essa circunstância pode ser percebida na turma em que não se realizou a atividade. Nela os estudantes apenas ouviam como a uma narração feita pelo professor, com os conteúdos a partir do livro didático, os alunos quietos ouvindo-o, a professora no papel de sujeito, narrando e os alunos no papel passivo, ouvindo. Nas palavras de Freire (2005, p 66),

\begin{abstract}
A narração de que o educador é o sujeito, conduz os educandos à memorização mecânica do conteúdo narrado. Mais ainda, a narração os transforma em "vasilhas", em recipientes a serem "enchidos" pelo educador. Quanto mais vá "enchendo" os recipientes com os seus "depósitos", tanto melhor educador será. Quanto mais se deixem docilmente "encher", tanto melhores educandos serão.
\end{abstract}

Nesta lógica, que Freire (2005) chama de distorcida, o autor observa que não há saber, que este só existe onde houver liberdade de pensamento, criatividade, inventividade o que gera o desejo e a busca pelo conhecimento. $\mathrm{O}$ que ficou bem caracterizado nas observações das turmas. Este resultado se manifestou também nos resultados da avaliação, momento em que a professora avaliou o mesmo conteúdo para as duas turmas de estudantes.

A bolsista confessa que ficou sensibilizada por não realizar a atividade com as duas turmas, porque a que não participou, pedia sempre para que pudessem participar também e era dissonante o envolvimento e a participação nas aulas. A aula com o uso das TICs realizada nessa investigação, não trouxe o problema recorrente das salas de aulas, nas quais os alunos quererem ficar telefonando, se distraindo, olhando os seus aparelhos, ou mesmo conversando entre si distraidamente. Acreditamos que se deva ao total envolvimento de todos na atividade, não restando tempo para isso, ou porque, de fato, despertou a curiosidade, a criatividade e integração total na ação. E, tendo um motivo certo, sentiram-se motivados para a ação que culminou em aprendizado. 


\section{CONSDERAÇÕES FINAIS}

A revisão bibliográfica destaca a importância das TICs no processo de aprendizagem dos conteúdos científicos. O mesmo ocorreu com esta investigação em campo, no contexto de uma escola pública. Ficou destacado também que os estudantes gostam de usa-las nas aulas, reforçando as pesquisas realizadas por autores como Moura e Brandão (2013), Kaieski, Grings e Fetter (2015) com resultados positivos neste sentido.

Com o desenvolvimento da atividade pode-se perceber que os alunos sentem falta de aulas mais dinâmicas. Percebe-se também que eles gostam e se sentem felizes por poderem utilizar tecnologias participando ativamente do processo de ensino-aprendizagem. $\mathrm{O}$ fato de terem que ir em busca de algo para colocar em prática, usar a sua criatividade, indicou que é muito importante para o aluno, mostrando que ele é capaz e que toda essa dinâmica, além do aprendizado, contribui na interação entre os colegas de classe.

Dentre as conclusões a que chegou-se, é clara a importância de se usar as tecnologias, com os estudantes não apenas no lugar de consumidores passivos, mas como produtores de conhecimentos e informações. No entanto, apesar das políticas para a inserção das TICs nas escolas, tanto alunos como professores ainda não fazem parte do processo, até porque muitas escolas não apresentam condições materiais para isso (GIASSI; TRAMONTIN, 2016). Esses recursos podem ser importantes no processo educativo, porém precisamos de práticas que contemplem uma intencionalidade pedagógica para contribuir com uma aprendizagem significativa.

Não interessa mudar apenas para uma aula mais atrativa, interessa sim, processos de ensino e aprendizagem que emancipem, que possibilitem a transformação do indivíduo para desafios do nosso tempo. Entendemos que para isso o professor, precisa incorporar novas práticas, especialmente no que tange a proporcionar ao aluno a possibilidade de criar, de produzir, encorajá-lo a ter curiosidade e deixá-lo utilizar o recurso tecnológico que tem à sua mão.

O uso de tecnologias poderá ter resultados surpreendentes, pois como destaca Freire (2011), o resultado vai depender d reflexão de questões como: Para que uso? Para quem uso? E porque uso? Pensar o emprego das tecnologias na escola é uma oportunidade de contribuir com as mudanças que principiam a surgir em nossos dias na educação.

\section{REFERÊNCIAS}

BELLONI, M. L. O que é mídia-educação. 2 ed. Campinas, SP: Autores Associados, 2005.

BRASIL. Orientações Curriculares para o Ensino Médio: Ciências da natureza, matemática e suas tecnologias. Secretaria de Educação Básica. Brasília, 2008.

FREIRE, P. Pedagogia da autonomia: saberes necessários à prática educativa. 13. ed. Rio de Janeiro: Paz e Terra, 2011.

FREIRE, P. Pedagogia do Oprimido. Rio de Janeiro: Paz e Terra, 2005. 
FREIRE, P.; PAPERT, S. O FUTURO da Escola - uma conversa sobre informática, ensino e aprendizagem. Produção da Pontifícia Universidade Católica de São Paulo - TV PUC. São Paulo: PUC-SP, 1995. Vídeo na Internet (60 min.), Formato MP4, son., color. Disponível em http://177.11.48.108:8080/xmlui/handle/7891/395 Acesso em: 29 ago. 2016.

GIASSI, M.; TRAMONTIN B. R. O Uso de Tecnologias no Ensino de Ciências e Biologia em Escolas da Rede Pública Estadual de Criciúma - SC. In: SEMANA DE CIÊNCIA E TECNOLOGIA DA UNESC, 2015.

KAIESKI, N.; GRINGS J. A.; FETTER S. A. Um estudo sobre as possibilidades pedagógicas de utilização do whatsapp. Novas tecnologias na educação v. 13, n. 2, dez. 2015.

LIBÂNEO, J. C.; Adeus professor, adeus professor? Novas exigências educacionais e profissão docente. 13. ed. São Paulo: Cortez, 2011.

MARTINHO, T.. POMBO, L. Potencialidades das TIC no ensino das Ciências

Naturais: um estudo de caso. Revista Electrónica de Enseñanza de las Ciencias. v.8, n. 2, p. 527-538, 2009.

MOURA, E. BRANDÃO, E. O uso das tecnologias digitais na modificação da prática educativa escolar. Revista Cientifica Fazer. v. 1, n. 1, p. 1-17, 2013.

MURPHY, C. (2003). Literature review in primary science and ICT. Bristol: Futurelab, 2003. Disponível em: 〈https://www.nfer.ac.uk/publications/FUTL73/FUTL73.pdf〉. Acesso em: 10 mar. 2016.

PERRENOUD, Philippe. 10 Novas competências para ensinar. Convite à viagem. Porto Alegre: Artmed, 2000.

MORAN, J.M.; MASETTO, M. T.; BEHRENS, M. A. Novas tecnologias e mediação pedagógica. Campinas: Papirus, 2000.

RAMOS, Márcio Roberto Vieira. O uso de tecnologias em sala de aula. Revista eletrônica LENPES - PIBID de Ciências Sociais - UEL. v. 1, n.2, jul-dez. 2012.

SANTOS, A. (2007). As TIC e o Desenvolvimento de competências para aprender a aprender. Disponível em: <https://ria.ua.pt/bitstream/10773/4766/1/2007001184.pdf>. Acesso em: 20 jul. 2016.

SERAFIM, Maria Lucia. SOUSA, Robson Pequeno de. Multimídia na educação: o vídeo digital integrado ao contexto escolar. Disponível em: < http://books.scielo.org/id/6pdyn/pdf/sousa-9788578791247-02.pdf.> Acesso em 29 jul. 2016.

SOFFNER, Renato. Tecnologia e educação: um diálogo Freire - Papert. Tópicos Educacionais, Recife, n.1, p. 147-162, jan./jun. 2013.

\section{Agradecimentos}

Nossos agradecimentos especiais à PROPEX - Programa de Pesquisa e Extensão da Unesc pelo apoio financeiro; à professora da Escola que partilhou conosco suas aulas e seus conhecimentos, aos estudantes que generosamente participaram desta investigação. Muito obrigada a todos. 